\title{
Assessment of Blood Pressure for Determining the Time to Perform First Postural Change in Patients after Cardiac Surgery in the Intensive Care Unit
}

\author{
Sachiko Nagaya ${ }^{1 *}$, Etsuko Fujimoto ${ }^{2}$ and Hiromitsu Kobayashi ${ }^{3}$ \\ ${ }^{1}$ Assistant Professor, Department of nursing, Graduate School of Medicine, Nagoya University, Japan \\ ${ }^{2}$ Professor, Department of nursing, Graduate School of Medicine, Nagoya University, Japan \\ ${ }^{3}$ Professor, Department of nursing, Ishikawa Prefectural Nursing University, Japan
}

"Corresponding author: Sachiko Nagaya, Nagoya University Graduate School of Medicine, Department of Nursing, 1-1-20 Daiko-minami, Higashi-ku, Nagoya city, Aichi 461-8673, Japan, Tel: +81-52-719-3102, E-mail: nagaya@met.nagoya-u.ac.jp

Received date: October 13, 2013, Accepted date: July 05, 2014, Published date: July 08, 2014

Copyright: (C) 2014 Nagaya S, et al. This is an open-access article distributed under the terms of the Creative Commons Attribution License, which permits unrestricted use, distribution, and reproduction in any medium, provided the original author and source are credited.

\begin{abstract}
Objective: Changing the posture of patients is an integral part of nursing care. However, postural changes after cardiac surgery can have potential adverse effects on patients. To prevent these effects, an appropriate assessment of the patient's condition is necessary. This study aimed to clarify the assessment by nurses to determine the timing to perform the first postural change in patients who have undergone cardiac surgery, with special reference to changes in blood pressure.
\end{abstract}

Methods: A qualitative study using semistructured interviews was conducted among registered nurses working in an intensive care unit of a hospital.

Results: Participants $(n=12)$ focused on four factors when interpreting a patient's blood pressure: "rewarming," "circulatory blood volume," "cardiac output," and "body movements." Participants assessed their patients based on two criteria: the first emphasizing specific blood pressure values and the second focusing on stability of the blood pressure, representing static and dynamic parameters, respectively. Nurses made an appropriate assessment by careful consideration of these two criteria.

Conclusion: The present results demonstrate that the assessment of blood pressure includes four factors. We propose that the assessment of dynamic changes in blood pressure are required in addition to the static status. This study may support nurse's assessment for the first postural change in patients after cardiac surgery.

\section{Key Words:}

Postural change; Intensive care nursing; Cardiac surgery; Clinical judgment; Hemodynamics; Early Ambulation; Qualitative research

\section{Introduction}

Prolonged bed rest leads to various complications in patients, including pneumonia [1], pressure ulcers [2], deep venous thrombosis [3], and joint contracture [4]. To avoid these, nurses regularly change their patients' postures. However, in critically ill patients, postural changes can potentially result in adverse effects on cardiorespiratory function, causing severe hypoxemia, increased oxygen demand, reduced cardiac output, hypotension, and arrhythmias [5]. These symptoms are particularly serious in patients who have undergone cardiac surgery. The hemodynamics of patients after cardiac surgery are often labile despite successful surgery, and such individuals remain at risk for low cardiac output, poor systemic vascular resistance, bleeding from incisions, and other issues [6].

Improvements in surgical procedures, anesthetic technique, and life support systems over recent years have reduced the level of surgical stress on patients undergoing cardiac surgery. These advances in cardiosurgery have made it possible to operate on the elderly and those with more severe illness who would have previously been considered unsuitable for undergoing such procedures. Therefore, the hemodynamics of postsurgical patients are now more severe compared with those previously observed. An appropriate assessment of cardiovascular function is needed when making postural changes in patients after cardiac surgery. However, it is particularly difficult for nurses to judge the time to perform the first postoperative postural change in patients who have undergone cardiac surgery. Therefore, the present study aimed to clarify the factors involved in such an assessment.

\section{Methods}

\section{Participants}

This study was conducted in a Japanese hospital with approximately 860 beds. Participants comprised 12 registered nurses working in an intensive care unit (ICU) of this hospital who had daily experience performing postural changes in patients. The average number of years of clinical nursing experience was 4.7 (range, 0.5-10.4) and that in the ICU was 3.8 (range, 1.3-10.4). Because it was crucial that we obtained the opinions of nurses who were used to making judgments concerning postural change, we asked the ICU nurse manager to recommend the most appropriate nurses who have adequate judgments and skills for this study. 


\section{Data collection}

Semistructured interviews were conducted after participants had performed a first postural change in a patient after cardiac surgery in the ICU. Each interview lasted from 12 to 58 min. Participants were interviewed after they were assigned to patients as part of their normal clinical practice. Questions were limited to information regarding the first postural change performed after cardiac surgery. One of the primary questions was as follows: "How did participants interpret information on blood pressure to determine the appropriate timing of the first postural change?"

\section{Data analysis}

The data were analyzed using a qualitative descriptive method. The recorded interviews were transcribed verbatim and examined several times to derive each participant's assessment accurately. The transcripts were divided into topics directly pertaining to the study's aim. That is, to reveal the process by which participants interpreted the blood pressure data collected from their patients before performing the first postural change. The topics related to blood pressure were classified according to each participant's assessment.

\section{Ethical considerations}

We obtained approval from the ethics committees of both the university and the hospital. The purpose and method of the study were explained to the nurse participants, and written informed consent was obtained from those who agreed to participate. They were informed that they could refuse to participate or withdraw from the study at any time.

\section{Results}

The 12 participants made 17 statements regarding the first postural change after cardiac surgery. These statements were coordinated and integrated by meaning, which revealed 13 main comments. These comments were grouped into four factors that concerned the assessment of blood pressure prior to determining the appropriate time for the first postural change.

The first factor was "rewarming." In regard to this factor, participants decided to perform the first postural change for patients after cardiac surgery in reference to blood pressure values in conjunction with changes in body temperature. Participants described simultaneously checking for the completion of rewarming and variation in blood pressure and reported that both recovery from hypothermia and stability of blood pressure were important. Some participants explained that blood pressure should remain stable for 1$2 \mathrm{~h}$ after the completion of the rewarming process.

\begin{tabular}{|c|c|}
\hline \multicolumn{2}{|l|}{ Rewarming } \\
\hline Comment A & $\begin{array}{l}\text { Patient's systolic blood pressure remained stable between } 90 \text { and } 100 \mathrm{mmHg} \text { after the completion of rewarming, and I believed that I could } \\
\text { perform the first postural change. }\end{array}$ \\
\hline Comment B & $\begin{array}{l}\text { I decided to perform the first postural change when I observed that the blood pressure of the patient remained stable for } 1-2 \mathrm{~h} \text { after the } \\
\text { completion of the rewarming process. }\end{array}$ \\
\hline Comment C & $\begin{array}{l}\text { I believe both body temperature and blood pressure to be the criteria for performing postural change in patients who have undergone cardiac } \\
\text { surgery. My patient's body temperature had increased to } 36.5^{\circ} \mathrm{C} \text {, and his blood pressure had stabilized. }\end{array}$ \\
\hline Comment D & $\begin{array}{l}\text { My patient had low blood pressure, but I assessed that he could tolerate postural change. It was true that his blood pressure was very low, } \\
\text { but his temperature normalized, and blood pressure was stable, although the value was low. Therefore, I decided to perform postural } \\
\text { change. }\end{array}$ \\
\hline Comment E & $\begin{array}{l}\text { In general, patient's blood pressure tends to be unstable during the rewarming process. If postural change is performed before the patient's } \\
\text { body temperature recovered, blood pressure sometimes changes. It becomes difficult for nurses to determine the reason for change in the } \\
\text { patient's blood pressure under such situations. We cannot identify the cause, if the patient presents with hypovolemia, low vascular tone, or } \\
\text { other symptoms. Thus, I performed the first postural change after the completion of rewarming and patient's when blood pressure appeared } \\
\text { stable. }\end{array}$ \\
\hline Comment $F$ & $\begin{array}{l}\text { I decided to perform postural change after the completion of rewarming. While the patient's body temperature had been recovering, I } \\
\text { believed hemodynamics status was still unstable. If I had performed postural change before the completion of the recovery process, there } \\
\text { was a possibility of hypotension. }\end{array}$ \\
\hline
\end{tabular}

Table 1: Comments provided by participants regarding rewarming.

"Circulatory blood volume" was identified as the second factor. Participants reported the importance of changes in effective circulating volume during postoperative management. Postoperative patients are sometimes hypovolemic because of continued blood loss related to intraoperative and postoperative third-space sequestration; therefore, participants considered the possibility of hypovolemia before performing postural changes to avoid the onset of hypotension (Table 2).

Circulatory blood volume

\begin{tabular}{|l|ll} 
Comment G & He was bleeding; however, there was no change in blood pressure in such a state. Thus, I decided to perform first postural change.
\end{tabular} 

during continuous bleeding, it may have precipitated hypotension.

Table 2: Comments provided by participants regarding circulatory blood volume.

The third factor was "cardiac output." Participants assessed the changes in cardiac output resulting from progression of treatments. They observed the trends in blood pressure in relation to the occurrence of arrhythmia or administration of inotropic drugs before performing postural change. Participants assessed low cardiac output secondary to arrhythmia (Table 3, Comment I) and monitored the effects of medications on the patients' cardiovascular function (Table 3 , Comment J)

\begin{tabular}{|l|l|}
\hline Cardiac output & \\
\hline Comment I & $\begin{array}{l}\text { I decided to perform postural change when I observed an improvement in arrhythmia in my patient in response to antiarrhythmic drugs } \\
\text { and a stabilized blood pressure. }\end{array}$ \\
\hline Comment $\mathbf{J}$ & $\begin{array}{l}\text { My patient required inotropic medication to maintain blood pressure. I did not perform first postural change until the medication was } \\
\text { effective and the patient's blood pressure rose. }\end{array}$ \\
\hline
\end{tabular}

Table 3: Comments provided by participants regarding cardiac output.

The final factor was "body movements." Participants observed whether blood pressure changes were synchronized with motion. Participants considered blood pressure changes that depending on their body movement, which suggested hemodynamic instability. They assessed that patients could tolerate positional change when blood pressure was stable, even when it was low. Participants attempted to detect signs of lowered blood pressure after postural change by observing changes in blood pressure associated with subtle movement (Table 4, Comment M)

\begin{tabular}{|l|l|}
\hline \multicolumn{2}{|l|}{ Body movements } \\
\hline Comment K & I used the blood pressure value that did not change with patient's body motion as a guide to perform first repositioning. \\
\hline Comment $\mathbf{L}$ & $\begin{array}{l}\text { His systolic blood pressure was low at } 80 \mathrm{mmHg} \text {; however, his blood pressure remained unchanged for } 1 \mathrm{~h}, \text { even though he awoke from } \\
\text { anesthesia and moved his body. Thus, I concluded that he could tolerate stimulation of postural change. }\end{array}$ \\
\hline Comment $\mathbf{M}$ & $\begin{array}{l}\text { My patient's blood pressure was low. However, his blood pressure did not change when he moved his arms and legs by himself. Patient's } \\
\text { blood pressure sometimes drops when he receives postural change. Therefore, I performed postural change at the time. }\end{array}$ \\
\hline
\end{tabular}

Table 4: Comments provided by participants regarding body movements.

Some participants commented on the practical criteria of postural change, e.g., "Patient's systolic blood pressure remained stable between 90 and $100 \mathrm{mmHg}$ " (Table 1, Comment A)or "I decided to perform the first postural change when I observed that the blood pressure of the patient remained stable for 1-2 $\mathrm{h}$ after the completion of the rewarming process" (Table 1, , Comment B)

\section{Discussion}

Our research revealed four factors related to the assessment of the patient's condition by participants, of which the most frequently mentioned was "rewarming." Patients who have undergone cardiac surgery are often hypothermic and require rewarming, but sometimes this leads to hemodynamic instability through vaso [7]. Our results suggest that rewarming is a key factor for nurses for the assessment of blood pressure when attempting the first postural change after cardiac surgery. Most participants focused on rewarming because the first postural change was often required during this period. If postural change was performed during the rewarming process, participants considered that this may put patients at potential risk for hemodynamic instability.
Two other factors (circulatory blood volume and cardiac output) are also important when defining the hemodynamic status of patients after cardiac surgery. Participants reported that they assessed the effects of vasoactive infusions and whether patients had recovered from hypovolemia. In addition, they ensured that the patients' blood pressures remained at an appropriate level of stability prior to attempting the first postural change.

The final factor related to body movement appears to be unique. Participants attempted to predict blood pressure changes by carefully observing subtle movements of the arms or legs of their patients. Even slight body movement can increase the strain on the heart in the immediate period after cardiac surgery. Postural change causes mixed venous oxygen saturation (SVO2) to decrease, which is attributable to the increased oxygen demand of muscular activity [8]; whole-body movements increase oxygen demands to a greater extent than peripheral movements do, leading to hemodynamic instability.

Anesthetics impact the activity of the autonomic nervous system [9-11], and postoperative patients requiring intensive care are sometimes put under sedation subsequently. The activity of the autonomic nervous system, which regulates the hemodynamic status of patients, is disturbed by these drugs [12]. When patients move or their posture is changed, they may become hemodynamically unstable 
because autonomic nerve responses are too weak to tolerate the stimulus. This is consistent with the observation by participants in this study that peripheral body movements could predict blood pressure fluctuations during postural changes.

When performing the first postural change, two criteria were associated with blood pressure. Some participants judged patients as able to tolerate overstimulation following the first postural change provided blood pressure changes were small. This included systolic blood pressures as low as $80 \mathrm{mmHg}$. However, others relied on specific blood pressure levels during their assessment, with a value above 90 $\mathrm{mmHg}$ being the key indicator of suitability for postural change.

Some studies have described the initiation of early patient mobilization [13-15] and provided blood pressure criteria to inform whether or not patients could tolerate mobilization. For example, the acceptable range of mean arterial blood pressure was reported as 60$110 \mathrm{mmHg}$ in one study [13], while a systolic blood pressure of less than $90 \mathrm{mmHg}$ was the key exclusion criterion elsewhere [14]. Another study emphasized the importance of stable blood pressure before mobilization, such as the absence of a recent change greater than 20\% [15]. The former [13,14] remarks on static status of cardiovascular functions, the later [15] on the other hand focuses on the dynamic change of the functions. These complementary approaches are consistent with the two criteria used by participants in this study.

The criterion using a specific blood pressure range may be particularly helpful for inexperienced nurses because this simplifies decision making [16]. However, there is considerable interindividual variation in blood pressure, and cardiovascular statuses are often complex and variable. If nurses judge the status of patients by static blood pressure values alone, an opportunity for early mobilization may be missed.

The present results demonstrate that the assessment of blood pressure included four factors: rewarming, circulatory blood volume, cardiac output, and body movements. We propose that it is important to assess dynamic changes in blood pressure in addition to static blood pressure values. This study provides experience-based guidance for the assessment of patients prior to the first postural change after cardiac surgery. The findings of this study may support nursing assessment.

This study was undertaken at one ICU and the number of participants in the study was small. Due to the small sample size, the opinions and results cannot be assumed to be representative of all ICU nurses. Our findings should be considered in light of this limited generalizability.

\section{Acknowledgment}

This study was partially supported by a Grant-in-Aid for Scientific Research (C) (No. 24593195) from the Japan Society for the Promotion of Science.

\section{References}

1. Drakulovic MB, Torres A, Bauer TT, Nicolas JM, Nogué S, et al. (1999) Supine body position as a risk factor for nosocomial pneumonia in mechanically ventilated patients: a randomised trial. Lancet 354: 1851-1858.

2. Lahmann NA, Kottner J, Dassen T, Tannen A (2012) Higher pressure ulcer risk on intensive care? - comparison between general wards and intensive care units. J Clin Nurs 21: 354-361.

3. Cook D, Attia J, Weaver B, McDonald E, Meade M, et al. (2000) Venous thromboembolic disease: an observational study in medical-surgical intensive care unit patients. J Crit Care 15: 127-132.

4. Clavet H, Hébert PC, Fergusson D, Doucette S, Trudel G (2008) Joint contracture following prolonged stay in the intensive care unit. CMAJ 178: 691-697.

5. Evans D (1994) The use of position during critical illness: current practice and review of the literature. Aust Crit Care 7: 16-21.

6. Currey J, Botti M (2005) The haemodynamic status of cardiac surgical patients in the initial 2-h recovery period. Eur J Cardiovasc Nurs 4: 207-214.

7. Toulson J (1994) Hypothermia. Accid Emerg Nurs 2: 186-192.

8. Gawlinski A, Dracup K (1998) Effect of positioning on $\mathrm{SvO} 2$ in the critically ill patient with a low ejection fraction. Nurs Res 47: 293-299.

9. Fleisher LA, Frank SM, Shir Y, Estafanous M, Kelly S, et al. (1994) Cardiac sympathovagal balance and peripheral sympathetic vasoconstriction: epidural versus general anesthesia. Anesth Analg 79: 165-171.

10. Shin WJ, Kang SJ, Kim YK, Seong SH, Han SM, et al. (2011) Link between heart rate and blood pressure Mayer wave during general anesthesia. Clin Auton Res 21: 309-317.

11. Kato M, Komatsu T, Kimura T, Sugiyama F, Nakashima K, et al. (1992) Spectral analysis of heart rate variability during isoflurane anesthesia. Anesthesiology 77: 669-674.

12. Ebert TJ (2005) Sympathetic and hemodynamic effects of moderate and deep sedation with propofol in humans. Anesthesiology 103: 20-24.

13. Perme C, Chandrashekar R (2009) Early mobility and walking program for patients in intensive care units: creating a standard of care. Am J Crit Care 18: 212-221.

14. Timmerman RA (2007) A mobility protocol for critically ill adults. Dimens Crit Care Nurs 26: 175-179.

15. Stiller K, Phillips A (2003) Safety aspects of mobilising acutely ill inpatients. Physiother Theory Pract 19: 239-257.

16. Ilott I, Rick J, Patterson M, Turgoose C, Lacey A (2006) What is protocolbased care? A concept analysis. J Nurs Manag 14: 544-552. 